\title{
Harberger-Laursen-Metzler Etkisi: Türkiye Ekonomisi Üzerine Ekonometrik Bir Analiz
}

\author{
Yelda Bugay TEKGÜL*
}

\begin{abstract}
ÖZ
Dış ticaret hadleri ile dış ticaret dengesi arasındaki ilişki iktisat literatüründe tartışmalı bir konu olmuştur. Bu tartışma Harberger (1950) ve Laursen ve Metzler'in (1950) çalı̧̧malarından bu yana süregelmektedir. Harberger-Laursen-Metzler (HLM) etkisi olarak bilinen ve üzerindeki tartışmaların sürdügü bu teorik görüş, dış ticaret hadlerindeki bir bozulmanın, dış ticaret dengesinde de bir bozulmaya yol açacağnı savunmaktadır. Dış ticaret hadlerindeki değişmelerin cari denge üzerindeki etkisi; dış ticaret hadlerinde yaşanan şokların süresi, bu değişmelerin beklenir olup olmadiğı ve bu şokların hangi iktisadi kanallarl kullanarak cari dengeyi etkilediği gibi faktörlere bağlıdır. Bu çalışmada 1982:1-2015:2 döneminde Türkiye'de hem mal ticaret hadleri hem de gelir ticaret hadlerindeki değişmelerin uzun dönem ticaret dengesi üzerindeki etkisi ARDL sinır testi ile araştırılmaktadır. Bu dönemde gelir ticaret hadlerinden diş ticaret dengesine doğru ayn yönde pozitif bir ilişki bulunurken, mal ticaret hadlerinden diş ticaret dengesine doğru negatif yönlü bir nedensellik ilişkisi olduğu sonucuna ulaşılmıştır.
\end{abstract} Yaklaşımı

Anahtar Kelimeler: Dış Ticaret Hadleri, Dış Ticaret Dengesi, HLM etkisi, ARDL Sınır Testi

Jel Kodu: F32, F41, E12

\section{The Harberger-Laursen-Metzler Effect: An Econometric Analysis On Turkish Economy}

\begin{abstract}
In literatüre of economics, the relationship between the trade balance and the terms of trade has always been a topic of debate. According to the Harberger-Laursen-Metzler (HLM) effect, an exogenous temporary increase in the terms of trade leads to an improvement in the current account balance. In economic theory, the relationship between the changes in terms of trade and the current balance depends on many factors. These are the duration of the shocks experienced in the terms of trade, temporary or permanent occurrence and these changes are expected or unexpected. This study investigates the relationship between terms of trade and trade balance in Turkey It employs commodity terms of trade and income terms of trade using a time series data set for the period 19822015 In this period, we investigate whether the HLM hypothesis is valid for the Turkish economy by the ARDL bounds test. The results show that there is a long-run and positive relationship from income terms of trade to trade balance and negative cousality relationship from commodity terms of trade to trade balance.
\end{abstract}

Keywords: Terms of Trade, Trade Balance, HLM Effect, ARDL Bounds Testing Approach

Jel Codes: F32, F41, E12

*Yrd. Doç. Dr., Çukurova Üniversitesi İ.̇̇.B.F. İktisat Bölümü, ttekgul@cu.edu.tr 


\section{GíRiş}

Dış ticaret hadleri (DTH); bir ülkenin sattı̆ğ ve satın aldığı malların fiyatlarındaki değişmeler sonucunda, dış ticaretten kazançlı çıkıp çıkmadığını gösteren önemli bir göstergedir. DTH ile diş ticaret dengesi arasındaki ilişkiyi açıklamaya yönelik çok sayıda teorik görüş bulunmaktadır. Bu görüşlerden bir tanesi Harberger-Laursen-Metzler (HLM) etkisi olarak bilinmekte ve ihracat fiyatlarının ithalat fiyatlarına oranı olarak tanımlanan DTH'deki bir bozulmanın, dış ticaret dengesinde de bir bozulmaya yol açacağı şeklinde ifade edilmektedir (Harberger, 1950; Laursen ve Metzler, 1950). ${ }^{1}$

$\mathrm{Bu}$ teorinin arkasındaki temel düşünce, dışa açık küçük bir ekonomi için DTH'deki bir iyileşmenin o ülkenin reel gelirini arttıracak olmasıdır. Harberger, Laursen ve Metzler'in kullandıkları Keynesyen tüketim fonksiyonu ile söz konusu ekonominin marjinal tüketim eğilimi birden küçük kabul edildiğinde sonuç olarak dış ticaret hadlerindeki bir iyileşmenin - tüketim harcamalarındaki artış cari gelirdeki artıştan daha küçük olacağı için - özel tasarruflarda bir artış ve dolayısıyla ticaret dengesinde bir iyileşme yaratacağ 1 beklenmektedir. Ekonomi literatüründe, diş ticaret hadlerindeki değişmeler ile cari denge arasındaki ilişkinin ve HLM etkisinin derecesinin birçok faktöre bağlı olduğu gözlenmektedir. Bu faktörler; dış ticaret hadlerinde yaşanan şokların süresi yani geçici veya kalıcı oluşu, bu değişmelerin beklenir olup olmadığı yani tahmin edilebilirliği ve bu şokların hangi kanallarla cari dengeyi etkilediği şeklindedir.

Çalışmamızın ilk kısmında HLM etkisi teorik ve ampirik yönden incelenmekte, daha sonraki bölümde bu etkinin varlığı Türkiye ekonomisi için, 1982:1-2015:2 dönemi ARDL sınır testi ile analiz edilmektedir.

\section{HLM ETKISII : TEORÍK VE AMPİRIK LITERATÜR}

HLM etkisi konusunda yapılan ilk çalışmalar gelir-harcama modelini esas almıştır. Gelir-harcama modelini esas alan çalışmalar, Keynesyen tüketim fonksiyonu çerçevesinde ve marjinal tüketim eğiliminin birden küçük olduğu varsayımı altında şu şekilde açıklanabilir: Dış ticaret hadlerindeki bir iyileşme ülkenin reel milli gelirini arttırarak iç üretimde bir artı̧̧ yaratacaktır. Ancak kısa dönem marjinal tüketim eğilimi birden küçük olduğundan, tüketim harcamalarındaki artış daha az olacaktır. Böylece özel tasarruflar artacak diğer koşullar sabitken bu durum diş ticaret dengesini olumlu yönde etkileyecektir. Diğer taraftan diş ticaret hadlerindeki bir bozulma, tasarruflarda bir azalmaya neden olacak bu da ticaret dengesini olumsuz etkileyecektir. Bu literatürün daha sonra yapılan katkılar sonucu önemli bulgularından bir tanesi de dış ticaret hadlerinde yaşanan şoklara dış ticaret dengesinin vereceği eş zamanlı tepkinin, bu şokların kalıcı olup olamamasına göre değişeceğidir (Otto, 2003:157).

HLM etkisi; dış ticaret hadleri bozulduğunda, net ihracat gelirinin ve tasarrufların azaldığını savunmaktadır. Dış ticaret hadlerindeki bir bozulma reel gelirde bir azalmaya yol açar. $\mathrm{Bu}$ durumda tüketiciler mevcut standartlarını koruyabilmek için marjinal tüketim eğilimlerini arttırarak tüketimlerinin aynı

\footnotetext{
${ }^{1}$ Bu çıkarımın tersi de doğrudur. DTH'de bir iyileşme Dış Ticaret Dengesinde bir iyileşme yaratmaktadır. 650
} 
seviyede sürmesini arzularlar. Marjinal tasarruf eğilimi ise azalır. Bu da ulusal tasarrufları azaltarak ve dış ticaret dengesini bozar (Turnovsky 1997'den aktaran: Misztal, 2010:129). Literatürde HLM etkisi üç aktarım kanalına ayrılarak gözlemlenebilir (Duncan, 2003:2-3):

Illk gözlem, çoğu teorik çalışmalarda tanımlanan tasarruf kanalıdır. Dış ticaret hadlerindeki değişmenin ülkedeki toplam tasarrufları değiştirerek cari dengeyi etkilemesidir. ${ }^{2}$ Sachs (1981)'e göre HLM etkisinin ölçüsü fiyat şoklarının sürekli olup olmamasına bağlı olacaktır. Bu etkiyi sadece dış ticaret hadlerindeki değişmenin geçici olması durumu ortaya çıkarabilmektedir. DTH'deki değişmenin kalıcı olması durumunda bu etkinin ortaya çıkması belirsiz olmaktadır. Çünkü bu tip sürekli değişmelerin sadece tüketimi değiştireceği ve yurtiçi tasarruflarda bir değişme yaratmayacağı ileri sürülmektedir.

İkinci gözlem, tasarruf-yatırım kanalıdır. Buna göre dış ticaret hadlerindeki değişme sadece yurtiçi tasarrufları değil -sermayenin marjinal verimliliğini değiştirerek- aynı zamanda yatırımları da pozitif veya negatif yönde etkileyerek cari dengeyi değiştirmektedir. ${ }^{3}$

Üçüncüsü ise literatürde en az vurgulanan kamu harcamaları kanalıdır. Buna göre dış ticaret hadlerinde ortaya çıkan bir değişme kamu harcamalarında pozitif veya negatif bir değişme yaratarak cari dengeyi olumlu veya olumsuz yönde etkilemektedir. ${ }^{4} \mathrm{Bu}$ mekanizma Tornell ve Lane (1994)'in çalışmasında test edilmiștir.

Şekil 1: Dış Ticaret Hadlerindeki Değişmelerin Cari Denge Üzerindeki Etki Kanalları

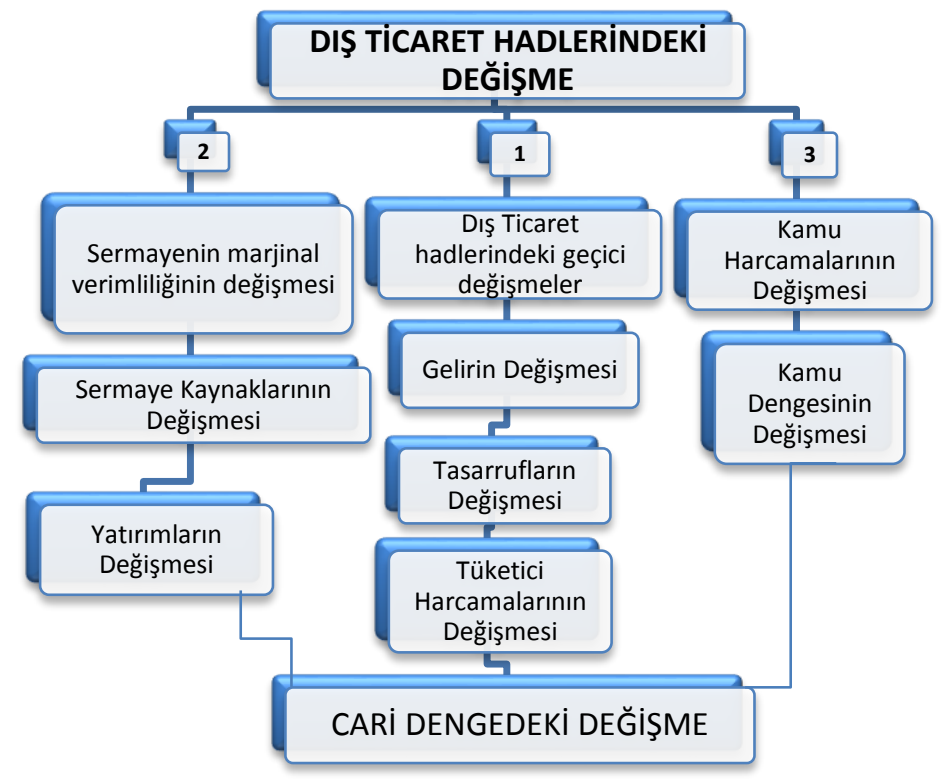

\footnotetext{
${ }^{2}$ Bu konuda yapılan çalışmalar için bkz. Laursen ve Metzler, 1950; Harberger, 1950; Sachs 1981; Obstfeld 1982

${ }^{3}$ Bu konudaki çalışmalar için bkz. Pearsson ve Svenson, 1985; Sen ve Turnovsky, 1989; Serven, 1999

${ }^{4} \mathrm{Kamu}$ harcamalarının pozitif etkilenmesi genellikle bir açığa, negatif etkilenmesi ise bir fazlaya karşılık gelmektedir.
} 
Kaynak: Misztal, P. (2010), s:132

Laursen ve Metzler'e göre, dış ticaret hadlerindeki bir bozulma birbirine zit iki etki yaratır. Bunlar gelir etkisi ve ikame etkisidir. Gelir etkisine göre, dış ticaret hadlerindeki bozulma ithal fiyatlarını yükselterek ve ihraç malının fiyatını düşürerek gelirde bir azalmaya yol açar. $\mathrm{Bu}$ durum toplam talebi (ulusal harcamalar1) olumsuz etkiler. İkame etkisine göre, ithal malı fiyatındaki bu yükselme, yurt içinde bu malların ikamelerinin üretimini teşvik ederek istihdamı ve geliri arttıracaktır. Dış ticaret hadlerindeki değişmenin dış denge üzerindeki net etkisi bu iki etkinin büyüklügüne bağlıdır. Gelir etkisi, ikame etkisinden büyük ise, diş ticaret hadlerindeki bu bozulma dış dengeyi de bozar. İkame etkisi gelir etkisinden büyük ise bu defa diş ticaret hadlerindeki bozulma, dış açığı azaltıcı etkide bulunur.

Ancak 1980'lerde HLM etkisinin varlığ1 deterministik dönemler arası optimizasyon çerçevesinde yeniden şekillendirilmiş ve bu etkinin mikro ekonomik esaslarının oluşturulması üzerinde durulmuştur. Dönemler arası yaklaşım, cari işlemler dengesinin ileriye dönük dinamik tasarruf ve yatırım kararlarından etkileneceğini ileri sürmektedir. Bu tür analizler Sachs (1981), Obstfeld (1982), Svensson ve Razin'in (1983) çalışmaları doğrultusunda 1980’li yıllarda yaygınlaşmıştır.

Obstfeld HLM etkisi konusunda yapılan ilk çalışmalardan farklı açıklamalar yapmıştır. Bu açıklamalara göre; DTH'deki bir bozulma tasarruflarda bir artışla sonuçlanacak ve dış ticaret bilançosunda bir iyileşme yaratacaktır. Dolayısıyla Obstfeld (1981)'e göre, HLM etkisinin genel geçerliliği sorgulanmalıdır. Obstfeld ayrıca kalıcı ve geçici dış ticaret hadleri şokları arasındaki farkın altını çizerek beklenmedik sürekli şokların HLM hipotezinin aksine diş ticaret dengesinde herhangi bir etki yaratmadığını ancak beklenmedik geçici şok durumunda HLM hipotezini destekler sonuçlar verdiğini belirtmiştir. Beklenmedik sürekli şoklar Obstfeld'e göre ulusal gelirin hem cari dönemde hem de gelecek dönemlerde azalmasına neden olacağı için diş ticaret dengesinde bir değişme yaratmayacaktır. Obstfeld'in de işaret ettiği gibi, HLM etkisi için ilk analizleri yapanlar önemli katkılarına rağmen DTH'deki değişmelerin tasarruflar, harcamalar ve cari açık üzerindeki etkilerinin tam analizini yapabilmede eksik kalmışlardır.

HLM etkisi, Modigliani ve Brumberg tarafindan ortaya atılan yaşamdöngüsü hipotezi ile açıklanırken, Obstfeld analizini Friedman'ın sürekli-gelir hipotezine dayandırmaktadır. Aslında her iki hipotez de tüketimin uzun dönemli gelirin düzeyi ile ilgili olduğu görüşünü paylaşmaktadır.

Ekonomik teori aslında dış ticaret hadleri ile cari denge arasındaki ilişkinin belirsiz olduğunun altını çizmektedir. Yapılan çalışmalarda dış ticaret hadlerinde yaşanan değişmelerin cari işlemler dengesini ne yönde etkileyeceği, belirli bir ölçüde bu şokların süresine (geçici veya kalıcı olmasına), aktörlerin bu şoklarla ilgili beklentilerine yani tüketicilerin bu şokları bekleyip beklemediklerine bağlı olarak değişeceğini göstermektedir.

Örneğin, Kent ve Cashin (2003)'ın 128 ülke için 1960-1999 yıllarını kapsayan çalışmalarında dış ticaret şoklarını geçici ve kalıcı olarak yaşayan ülkeler 
olmak üzere iki tip ülke grubu belirlemişlerdir. Şokların cari işlemler dengesi üzerindeki etkisi dönemler arası modellerde incelenirken analize tüketim düzleştirme ve yatırımların şoklara karşı tepkisi dâhil edilmiştir. Yazarların bulgularına göre, diş ticaret hadlerindeki şokların kalıcı olduğu durumda "yatırımların etkisi”, tasarrufları belirleyen tüketim düzleştirme etkisine göre daha fazla olmaktadır. Bu nedenle cari işlemler dengesi, şoklar süreklilik kazandığında bu durumdan daha az etkilenmektedir.

Cashin ve McDermott (1998) çalışmalarında ortaya koydukları sonuç, dış ticaret hadlerinde yaşanan geçici negatif bir şok durumunda gelir etkisine göre o ülkenin dış ticaret dengesi bozulurken, ikame etkisiyle dış ticaret dengesi iyileşmektedir. Burada önemli olan net etkidir.

Backus (1994) sanayileşmiş ülkeler için diş ticaret hadleri ile diş ticaret dengesi arasında pozitif bir korelasyon bulmuştur. Mendoza (1995) ise, dış ticaret hadlerindeki değişmenin reel gelir ve diş ticaret dengesi üzerindeki etkisini etkitepki fonksiyonunu kullanarak analiz etmiştir. G7 ülkeleri ve 23 gelişmekte olan ülkeyi kapsayan analiz sonuçlarına göre dış ticaret hadlerinde yaşanan bir iyileşme reel gelirde bir artış ve dış ticaret dengesinde bir iyileşme ile sonuçlanmaktadır. Mendoza'ya göre, dış ticaret hadlerinde yaşanan şoklar sürekli olduğu zaman, dış ticaret dengesinde üzerindeki etkileri azalmaktadır

Kent (1997) panel veri analizini kullanarak yaptığı çalışmada daha az kalıcı dış ticaret hadleri şoklarının yaşandığı ülkelerde bu şoklar ile dış ticaret dengesi arasında pozitif bir ilişki olduğunu, diğer taraftan daha fazla kalıcı şoklar yaşayan ülkelerde bu ilişkinin zayıfladığını savunmaktadır.

Ancak gelişmiş ülkeler için yapılan analizler ile gelişmekte olan ülke gruplarında yapılan analizler farklı sonuçlar vermektedir. Idrees ve Tufail (2012), Pakistan için HLM etkisini araştırdıkları 1980-2008 dönemini kapsayan çalışmada, iki önemli sonuca ulaşmışlardır. İlki reel gelirin dış ticaret hadlerindeki bir iyileşme ile bozulduğu ikincisi cari işlemler dengesinin dış ticaret hadlerindeki değişmelere olumsuz cevap vermesidir. Bu da Pakistan için analiz döneminde HLM etkisinin bulunmadığını göstermektedir. Elde edilen etki-tepki fonksiyonuna göre, dış ticaret hadlerinde yaşanan pozitif bir şok reel çıktıda negatif bir etki yaratmaktadır. Buradan da ulusal paranın değer kazanmasının bu ülkede bir süre sonra Hollanda Hastalığına ${ }^{5}$ neden olabileceği tespiti yapılmıştır (Hermandez, 2011'den aktaran: Idrees ve Tufail, 2012:102).

Gelişmekte olan ülkelerin asıl ihracatları, düşük fiyat talep esnekliğine sahip ilkel mallar olduğundan, bu tip ülkelerin dış ticaret hadlerindeki bir iyileşmenin ekonomilerinde büyüme yaratacağı şüphelidir. Sonuç olarak diş ticaret hadlerindeki bir iyileşmenin, gelişmekte olan ülkelerde her zaman olumlu sonuçlar

\footnotetext{
${ }^{5}$ Spatafora ve Warner tarafindan 1995 yılında yapılan çalışmada, "ticaret hadlerinin yükselmesinin doğal kaynak zengini ülkelerin ulusal paralarında değer artışlarına neden olduğu ifade edilmiştir. Bu süreçte kısa vadeli sermaye girişleri ile reel efektif döviz kurunun düşmesi ulusal paranın değerini artıırken, tüketim artmakta, ticarete konu olmayan mal ve hizmetlere de talep artmaktadır. Bir anlamda ulusal paranın değer kazanmasıyla birlikte ülke rekabet avantajinı yitirmekte, ihracat azalmakta ve ithalatla rekabet edemez hale gelmektedir. Bunun sonucunda yatırım yapılamamakta, işsizlik, dolayısıyla yoksulluk oranı artmaktadır. Bu durum Hollanda Hastalı̆ı̆ olarak adlandırılmaktadır.
} 
vermeyebileceği göz ardı edilmemelidir. Birçok yazara göre, diş ticaret hadlerindeki bir iyileşmeden doğan kazanç bu tip ülkelerde gereksiz alanlarda harcanabilmektedir. Ayrıca önemli bir başka nokta da, gelişmekte olan ülkelerin yurtiçi üretimlerini sürdürebilmek için petrol ürünleri, makine ve sermaye-yoğun malları ithal etmek zorunda olmalarıdır.

Otto'nun 15 küçük OECD ülkesi ve 40 gelişmekte olan ülkeyi ele aldığ 1960-1997 yıllarını kapsayan ve VAR modeli kullanılarak yaptığı çalışmada, dış ticaret hadlerindeki bir iyileşmenin hem gelişmiş hem de gelişmekte olan ülkelerde dış ticaret dengelerini bir yıl gibi bir sürede olumlu etkilediği yönünde bulgular elde etmiştir. Bu sonuçlar hem gelişmekte olan hem de gelişmiş küçük açık ekonomiler için HLM etkisinin olduğu yönünde önemli destekleyici bulgulardır. Ancak dış ticaret hadlerindeki şoklar daha kalıcı hale geldiğinde bu etki ortadan kalkmaktadır. Otto'nun sonuçlarından biri de gelişmekte olan ülkeler açısından bakıldığında diş ticaret hadlerinde yaşanan ortalama şokların ticaret dengesindeki dalgalanmaları açıklamakta göreli olarak gelişmiş ülkelere göre daha fazla önem taşımakta olduğudur. OECD ülkeleri içerisinde diş ticaret hadlerinde yaşanan şokların ticaret dengesi üzerindeki etkilerinin en fazla olduğu ülkelerin, Avusturalya ve Yeni Zelanda gibi ilkel mal ihracatları fazla olan ülkeler olduğu dikkati çekmektedir (Otto, 2003:162-176).

Diğer taraftan Mistzal 2010 yılındaki çalışmasında, Eicher, Schubert ve Turnovsky (2008) çalışmasına gönderme yaparak, bir ekonominin dış ticaret hadlerindeki değişmelere tepkisinin öncelikle bu ülkenin dünyanın geri kalan ülkelerine karş1 net alacaklı mı yoksa borçlu mu olduğuna bağlı olduğunu vurguladıklarını belirtmektedir (Mistzal, 2010:133).

Benzer bir şekilde Svensson ve Razin (1983) de, eğer ekonomi net diş alacaklı ve uluslararası faiz oranları ortalama değerin üzerinde ise; bireylerin bu yüksek faiz karşısında tüketimlerini düzleştirecekleri için cari işlemler fazlası verileceğini diğer bir deyişle tasarrufların artacağını ileri sürmüşlerdir. Eğer net dış borçlu durumunda iseler, geçici olarak yüksek olan faiz oranları cari işlemler üzerinde ters yönlü bir etkiye neden olacaktır.

Tablo 1: Dış Ticaret Hadlerindeki Değişmelerin Olası Etkileri

\begin{tabular}{|l|l|l|}
\hline \multicolumn{3}{|c|}{ Geçici Bir Bozulma Durumu Ticaret Hadleri } \\
\hline \multicolumn{2}{|c|}{} & \multicolumn{1}{c|}{ Kalıcı Bir Bozulma Durumu } \\
\hline -Reel Gelir Azalır & $\begin{array}{l}\text {-Reel faiz oranlarındaki değişme } \\
\text { (ikame etkisi) }\end{array}$ & $\begin{array}{l}\text {-Reel gelir azalır, tüketim aynı oranda } \\
\text { azalır; Tasarruflar üzerindeki etkisi } \\
\text { belirsizdir }\end{array}$ \\
-Harcamalar Artar & -Düşme: tasarruflar düşer, tüketim \\
(tüketimin düzleşmesi & artar, cari denge bozulur \\
etkisi) & -Yükselme: Tasarruflar artar, \\
-Dış Ticaret Bilançosu & tüketim azalır, cari denge düzelir \\
Bozulur & & \\
\hline
\end{tabular}


Türkiye ekonomisi için diş ticaret hadleri ve cari işlemler dengesi konusunda yapılan çalışmalardan Kıpıcı (1996), 1988-1995 dönemini kapsayan ve HLM etkisini test ettiği çalışmasında bu dönem için söz konusu hipotezin geçerli olmadığı sonucuna ulaşmıştır.

Yamak ve Korkmaz (2006) benzer bir şekilde HLM Hipotezinin 1991-2003 dönemi Türkiye ekonomisi için geçerliliğini sınamışlardır. Bu çalışmalarında dış ticaret haddinde meydana gelen bir iyileşmenin reel diş ticaret dengesinde üç ay içinde bir kötüleşme yarattığını, ikinci üç ay içerisinde tekrar durağan-durum seviyesine geri dönüldügünü belirlemişlerdir.

Oktar ve Dalyanc1 (2012), 2004-2011 dönemini kapsayan analizlerinde diş ticaret hadleri ve cari işlemler dengesi arasında uzun dönemde eş-bütünleşme ilişkisi tespit etmişlerdir. Analiz sonuçları, uzun dönemde diş ticaret hadlerinde sağlanacak iyileşmelerin, cari işlemler dengesini de iyileştireceği sonucunu göstermektedir. Kısa dönemde ise herhangi bir nedensellik ilişkisi belirlenememiştir.

\section{HARBERGER-LAURSEN-METZLER ETKİSININ TÜRKIYYE IÇİN ANALIZİ}

Literatürde uzun dönemde diş ticaret hadleri ile bunun ticaret dengesine doğrudan etkileri üzerinde odaklanan ekonometrik çalışmalar bulunmakla birlikte çoğu çalışma temel olarak "mal ticaret hadlerini”" ele almaktadır. Mal ticaret hadleri aynı zamanda "net değişim ticaret hadleri" olarak da tanımlanmaktadır. Kavram, ihracat fiyatlarının ithalat fiyatlarına oranlanması şeklinde ifade edilmektedir. Dış ticarete konu olan mallar çok sayıda olduğu için ihracat ve ithalat fiyatları endekslerle ifade edilmektedir. Diğer koşullar sabitken, ihracat fiyatlarındaki artış ithalat fiyatlarındaki artış oranından fazla olduğu sürece dış ticaret hadleri ülkenin lehine bir gelişme gösterecektir.

Dış ticaret hadlerinin diğer bir ölçüm şekli "gelir ticaret hadleridir." Gelir ticaret hadleri, ihracat fiyatlarının ihracat hacmiyle çarpılarak ithalat fiyatlarına bölünmesi şeklinde hesaplanmaktadır. Diğer bir deyişle, gelir ticaret hadleri yaklaşık olarak, ihracat hacminin ithalat fiyatına (ithalat birim değerine) bölümü şeklinde de tahmin edilebilmektedir. Burada göz ardı edilmemesi gereken bir nokta, ihracat fiyat değişmelerinin gelir ticaret hadleri üzerindeki net etkisinin, ihracat hacmindeki değişmeye de bağl1 olduğudur. Ülkenin ithalat kapasitesini ihracat yoluyla gösterdiği için ihracatın satın alma gücünü göstermektedir. Bu nedenle bu tanıma " ihracata dayalı ithalat kapasitesi endeksi" de denilmektedir. ${ }^{6}$

Gelir ticaret hadlerindeki değişme, söz konusu ülkenin diş ticarette güçlü olma durumuna göre ve bir anlamda dış dünyanın söz konusu ülke mallarına olan dış talep esnekliğine bağlı olarak değişecektir. Şayet ihraç mallarına olan dış talep

\footnotetext{
${ }^{6}$ Dış ticaret kazançları bakımından, fiyatlardaki değişmelerin, verimlilikten kaynaklanıp kaynaklanmadığının da önemi vardır. Bu durum “ faktör ticaret hadleri” kavramıyla giderilmeye çalışılmıştır. Bu tanım, net değişim ticaret hadlerinin, ihracat kesimindeki verimlilik endeksi ile çarpılmasını ifade etmektedir. Ancak uygulamada kaynakların verimlilik değişmelerini hesaplamanın önemli zorlukları bulunmaktadır.
} 
esnekliği düşük ise ve net değişim ticaret hadleri yükselmişse ülke refahının mutlak olarak arttığı sonucuna varılabilir. Ancak ihraç mallarına olan dış talep esnekliği yüksek iken, net değişim ticaret hadlerinin yükselmesi durumunda ihracat hacmi düşecek bu da refahı olumsuz etkileyecektir. Gelir ticaret hadleri arttığında ihraç mallarına olan dış talep esnekliği birden küçük ise, ihracat hacmi değişmeyecek ve sonuçta toplam gelir artacaktır. Bu da diş dengeyi olumlu yönde etkileyecektir. Tersine gelir ticaret hadleri bozulduğunda ihraç mallarının dış talep esnekliği katı iken, ihraç malları fiyatı düşse de ihraç edilen mal miktarındaki artış aynı düzeyde olmayacağından dış denge olumsuz etkilenecektir.

Mal ticaret hadleri sadece ihracat ve ithalat fiyatları arasındaki ilişkiye odaklanırken, gelir ticaret hadleri ülkenin ihracat miktarına bağlı olarak ithalat miktarı kapasitesini ölçmektedir ve buna göre dış ticaret hadleri değişecektir. Mal ticaret hadlerindeki bir artış ihracat fiyatlarının ithalat fiyatlarına göre daha yüksek olduğunu veya bir birim ihraç malıyla daha fazla miktarda ithalat malı alınabileceğini göstermektedir. Ancak, mal ticaret hadleri ve gelir ticaret hadleri aynı yönde hareket etmek zorunda değildir. İhracat fiyatlarındaki göreli bir artış aynı zamanda ihracat miktarındaki bir azalışla birlikte gözleniyorsa mal ticaret hadlerindeki düzelme gelir ticaret hadlerindeki gerileme ile dengelenecektir. $\mathrm{Bu}$ nedenle ticaret dengesinde bir düzelme söz konusu olmayacaktır. Aynı ülke için mal ticaret hadlerindeki pozitif bir gelişme, ihracat miktarındaki bir artış ile destekleniyorsa, bu durumda gelir ticaret hadleri mal ticaret hadlerine göre daha fazla yükselecektir (Appleyard ve Field, 2001'den aktaran: Tsen, 2006:308).

\section{A. Yöntem ve Veri Tanımlaması}

Çalışmada ticaret dengesi $\left(T B_{t}\right)$ aşağıdaki şekilde ifade edilmiştir: ${ }^{7}$

$T B_{t}=\left[\left(X_{t} / P_{x t}\right) /\left(M_{t} / P_{m t}\right)\right]$

$X_{t}, \mathrm{t}$ dönemindeki ihracat değerini; $M_{t}$, t dönemindeki ithalat değerini, $P_{x t}$ ihracat fiyatı, $P_{m t}$ ithalat fiyatını ifade etmektedir $\left[P_{x t}\right.$ ve $P_{m t}$ birim değer endeksi olarak $(2010=100)$ alınmıştır].

Çalışmada dış ticaret hadleri, mal ticaret hadleri (TOT1) ve gelir ticaret hadleri olarak (TOT2) ayrı ayrı analiz edilmiş olup buna göre:

Mal ticaret hadleri (TOT1):

$$
\text { TOT1 }=\left(P_{x t} / P_{m t}\right) * 100
$$

Formülden anlaşılacağ gibi ithalat fiyat endeksi $P_{m t}$ sabitken ihracat fiyat endeksinin $P_{x t}$ yükselmesi durumunda net değişim ticaret hadleri ülke lehine döner böylece söz konusu ülke bir birim ihraç mal karşıllı̆ında artık daha fazla miktarda ithal mal elde eder, bu da ülkenin refahında bir artış olarak yorumlanabilir.

Gelir Ticaret Hadleri (TOT2):

\footnotetext{
${ }^{7}$ Ticaret dengesinin hesaplanmasında, Wong H. Tsen, (2006) çalışmasında kullanılan formülden faydalanılmış̧ır. 656
} 
TOT2 $=\left(X_{t} / P_{m t}\right) * 100$ İle ifade edilmektedir.

Diğer bir deyişle: TOT2 $=\left\{\left(P_{x t} * Q_{x t}\right) / P_{m t}\right\} * 100$

$\mathrm{Bu}$ çalı̧̧manın amacı 1982-2015 yılları arasında Türkiye'deki hem mal ticaret hadleri hem de gelir ticaret hadlerindeki değişmelerin, uzun dönem ticaret dengesi üzerindeki etkisini analiz edebilmektir. İhracat ve ithalat değerleri dolar cinsinden üçer aylık veriler olarak TÜIK'ten derlenmiş olup $(2010=100)$, ihracat ve ithalat birim değer endeksleri de TÜIK'ten yine üçer aylık veriler olarak alınmıştır. Birim değer endeksinde, malların herhangi bir döneme ait ihracat ve ithalat toplam değerlerinin toplam miktarlarına bölünmesiyle elde edilen ortalama birim değerler kullanılarak endeks hesaplanmaktadır. Dolayısıyla ihracat ve ithalat fiyat endeksi yerine kullanılmaktadır.

\section{B. Model ve Ampirik Bulgular}

Türkiye ekonomisi için 1982:Q1-2015:Q2 yıllarını kapsayan dönemde dış ticaret hadlerindeki değişmenin (mal ticaret hadleri ve gelir ticaret hadleri olmak üzere ayrı ayrı incelenmiştir.) cari işlemler dengesi üzerindeki etkileri kısa ve uzun dönemde ARDL (Autoregressive Distribution Lag) yöntemiyle incelenmiştir.

Çalışmada kullandığımız model:

$$
\begin{aligned}
& T B_{t}=\propto_{1}+\propto_{2} \text { TOT }_{t}+\mu_{t} \\
& T B_{t}=\beta_{1}+\beta_{2} \text { TOT } 2_{t}+\varepsilon_{t}
\end{aligned}
$$

$\mathrm{TOTI}_{t}=$ Mal ticaret hadleri serisi; $\mathrm{TOT}_{t}=$ Gelir ticaret hadleri serisi;

$T B_{t}=$ Cari işlemler dengesi serisini temsil etmektedir.

Durağanlık zaman serisi analizlerinde özel bir önem kazanmaktadır. Stokastik özellik serilerin durağanlı̆̆ ile ilgilidir. Bir zaman serisinin durağan olması, zaman içinde belirli bir değere doğru yaklaşması yani sabit bir ortalama, sabit varyans ve gecikme seviyesine bağlı kovaryansa sahip olmasıdır. Durağan olmayan zaman serileri ile çalışıldığında sahte regrasyon problemiyle karşılaşılabilmektedir. Çalışmamızda da benzer sorunla karşıllaşıldığ 1 için Pesaran, Shin, Smith (2001) tarafından ortaya konan sınır testi yaklaşımı esas alınmıştır. Bu yaklaşıma göre serilerin $I(0)$ veya $I(1)$ olmalarına bakılmaksızın seriler arasında eşbütünleşme ilişkisinin varlığı sınanabilmektedir. Bunun için ise öncelikle hata düzeltme modeli oluşturulmaktadır:

$$
\begin{aligned}
\Delta T B_{t} & =\propto_{0}+\sum_{i=1}^{m} \propto_{1 i} \Delta T B 1_{t-i}+\sum_{i=0}^{m} \propto_{2 i} \Delta T O T 1_{t-i}+\propto_{3} e c m+u_{t} \\
\Delta T B_{t} & =\beta_{0}+\sum_{i=1}^{m} \propto \beta_{1 i} \Delta T B 1_{t-i}+\sum_{i=0}^{m} \beta_{2 i} \Delta T O T 2_{t-i}+\beta_{3} e c m+\varepsilon_{t}
\end{aligned}
$$

Kısıtlanmamış hata düzeltme modelinde $(\mathrm{ecm}), m$ gecikme sayısını ifade etmektedir. Gecikme sayısının belirlenmesi için Akaike ve Schwarz kriter değerlerinden yararlanılmıştır. Akaike kriterine göre en küçük kriter değerini sağlayan gecikme uzunluğu modelin gecikme uzunluğu olarak belirlenmiştir.

Tablo 2: Gecikme Sayısının Belirlenmesi

\begin{tabular}{|c|c|c|}
\hline $\mathbf{m}$ & AIC & SBC \\
\hline
\end{tabular}




\begin{tabular}{|c|c|c|}
\hline $\mathbf{1}$ & $\mathbf{2 1 2 . 6 7}$ & $\mathbf{2 0 6 . 9 9}$ \\
\hline $\mathbf{2}$ & 221.47 & 210.13 \\
\hline $\mathbf{3}$ & 235.83 & 218.81 \\
\hline $\mathbf{4}$ & 259.05 & 236.36 \\
\hline $\mathbf{5}$ & 265.66 & 237.30 \\
\hline $\mathbf{6}$ & 268.70 & 234.66 \\
\hline $\mathbf{7}$ & 266.63 & 226.92 \\
\hline $\mathbf{8}$ & 264.90 & 219.52 \\
\hline AIC: Akaike Bilgi Kriteri, SBC: Schwarz Bilgi Kriteri \\
\hline
\end{tabular}

Tablo 2'de AIC ve SBC'a göre gecikme uzunluğu 1 olarak seçilmiştir. Gecikme uzunluğu belirlendikten sonra eşbütünleşme ilişkisinin varlığının test edilebilmesi iç ARDL sınır testi uygulanmıştır. Bu test için temel hipotez $\mathrm{H}_{0}: \alpha_{4}=\alpha_{5}=0$ kurularak hesaplanan $\mathrm{F}$ istatistiği, Pesaran, Shin, Smith (2001)'deki tablo alt ve üst kritik değerleri ile karşılaş̧ırılmıştır. Hesaplanan F istatistiği Pesaran üst kritik değerinin üzerindeyse "seriler arasında eşbütünleşme ilişkisi vardır" yorumu yapılabilir. Seriler arasında eşbütünleşme ilişkisi bulunduktan sonra uzun dönem ilişkileri belirlemek için ARDL (Autoregressive Distributed Lags) modeli kurulmuştur. Tablo3'te yer alan $\mathrm{F}$ istatistiği sonucuna göre her iki model için de \%5 önem düzeyinde eş-bütünleşme ilişkisinin varlığı kabul edilmiştir.

Tablo 3: Sinır Testi

\begin{tabular}{|l|c|c|}
\hline & TB-TOT1 & TB-TOT2 \\
\hline Hesaplanan F istatistiği & $12,30 * *$ & $7,05 * *$ \\
\hline $\begin{array}{l}\text { Örnekleme göre düzeltilmiş kritik değerler }(* *) \% 5: 5,01-5,83 \text { (Microfit } 5,0 \text { 'da } \\
\text { hesaplanmıştır). }\end{array}$
\end{tabular}

Eşbütünleşme ilişkisinin varlı̆̆ına ilişkin kanıtlara ulaşıldıktan sonra her değişken için gecikme sayıları serbest bırakılarak uzun dönem katsayılar aşağıdaki modellerde olduğu gibi tahmin edilmiştir. Mal ticaret hadleri ve gelir ticaret hadleri ile dış ticaret dengesi arasındaki uzun dönem ilişsinin incelenmesi için sırasıyla ARDL modeli aşağıdaki şekilde kurulmuştur.

$$
\begin{aligned}
& T B=\propto_{0}+\sum_{i=1}^{m} \propto_{1 i} T B_{t-i}+\sum_{i=0}^{n} \propto_{2 i} \text { TOT } 1+\mu_{t} \\
& T B=\beta_{0}+\sum_{i=1}^{m} \beta_{1 i} T B_{t-i}+\sum_{i=0}^{n} \beta_{2 i} \text { TOT } 2+\varepsilon_{t}
\end{aligned}
$$


Tablo 4: ARDL (3,3) Modeli Uzun Dönem Katsayıları (TB-TOT1)

\begin{tabular}{|c|c|c|}
\hline Değişken & Katsayı & p-değeri \\
\hline Sabit terim & 3,838 & 0,000 \\
TOT1 & $-0,931$ & 0,001 \\
\hline
\end{tabular}

Tablo 4'te AIC kriterine göre en uygun model olduğu belirlenen ARDL $(3,3)$ modelinden elde edilen mal ticaret hadleriyle (TOT1) ticaret dengesi (TB) arasındaki uzun dönem katsayılar gösterilmektedir. Çalışmamızda değişkenler arasında uzun dönem ilişkisinin analizinde TOT1 ve TB arasındaki uzun dönem katsayılarına göre ilişki negatif ve istatistiksel olarak anlamlı bulunmuş olup, mal ticaret hadlerinde oluşacak \%1'lik olumlu bir değişme ticaret dengesini yaklaşık olarak kendisi kadar (bu değişmenin \%93'ü kadar) bozmaktadır.

Tablo 5: ARDL(3,3) Modelinden Elde Edilen Hata Düzeltme Modeli Sonuçları (TBTOT1)

\begin{tabular}{|c|c|c|}
\hline Değișken & Katsay1 & p-değeri \\
\hline Sabit terim & 1,347 & 0,006 \\
\hline dTB1 (-1) & 0,231 & 0,009 \\
\hline dTB (-2) & $-0,120$ & 0,169 \\
\hline dTOT1 & $-0,677$ & 0,003 \\
\hline dTOT1 (-1) & $-0,397$ & 0,094 \\
\hline dTOT1 (2) & 0,367 & 0,123 \\
\hline ecm(-1) & $-0,341$ & 0,000 \\
\hline
\end{tabular}

Değişkenler arasındaki uzun dönemli katsayılar tahmin edildikten sonra ARDL $(3,3)$ 'den elde edilen hata düzeltme modeli sonuçları Tablo 5 'te verilmiştir. ecm(-1)'in katsayısı kısa dönemdeki dengesizliğin ne kadarının izleyen dönemde düzeldiğini göstermektedir. Buna göre kısa dönemde hata düzeltme terimi negatif ve istatiksel olarak anlamlı olup, oluşan bir dengesizlik durumunda ilk dönemde dengesizliğin \%34'ü giderilmekte ve yaklaşık üç dönemde dengeye gelinmektedir.

Tablo 6: ARDL(2,6) Modeli Uzun Dönem Katsayıları (TB-TOT2)

\begin{tabular}{|c|c|c|}
\hline Değişken & Katsay1 & p-değeri \\
\hline Sabit terim & $-3,070$ & 0,002 \\
TOT2 & 0,104 & 0,011 \\
\hline
\end{tabular}

Gelir ticaret hadlerindeki bir değişmenin etkisine baktığımız analiz sonuçlarına göre ise uzun dönemde istatistiksel olarak anlamlı ve aynı yönde bir ilişki bulunmuş olup sonuçlar gelir ticaret hadlerindeki (TOT2) \%1'lik değişmenin ticaret dengesinde bu değişimin \%10’u oranında bir değişiklik yarattığını ortaya koymaktadir.(Tablo 6).

Tablo 7: ARDL(2,6)'dan Elde Edilen Hata Düzeltme Modeli Sonuçları (TB-TOT2)

\begin{tabular}{|c|c|c|}
\hline Değişken & Katsay1 & p-değeri \\
\hline Sabit terim & 0,658 & 0,026 \\
\hline dTB(-1) & 0,221 & 0,013 \\
\hline dTOT2 & 0,372 & 0,002 \\
\hline
\end{tabular}




\begin{tabular}{|c|c|c|}
\hline dTOT2 $(-1)$ & $-0,022$ & 0,865 \\
\hline dTOT2 $(-2)$ & 0,021 & 0,864 \\
\hline dTOT2 $(-3)$ & 0,088 & 0,466 \\
\hline dTOT2 (-4) & 0,102 & 0,394 \\
\hline dTOT2 (5) & 0,342 & 0,002 \\
\hline Ecm & $-0,261$ & 0,000 \\
\hline
\end{tabular}

TB-TOT2 modeli için değişkenler arasındaki uzun dönemli katsayılar tahmin edildikten sonra ARDL $(2,6)$ 'dan elde edilen hata düzeltme modeli sonuçları Tablo 7'de verilmiştir. Kısa dönemde ise, hata düzeltme terimi beklendiği gibi negatif ve istatiksel olarak anlamlı bulunmuş olup oluşacak bir dengesizlik durumunda ilk dönemde dengesizliğin \% 26'sı giderilmekte ve yaklaşık dört dönem içerisinde dengeye dönülmektedir.

\section{SONUÇ}

Literatürde diş ticaret hadlerindeki değiş̧meler ile cari işlemler dengesi arasında belirsiz bir ilişki olduğu gözlenmektedir. Dış ticaret hadlerindeki değişmelerin cari işlemler dengesini ne yönde ve ne ölçüde etkileyeceği şokların süresi, dış ticaret hadlerindeki değişmelerin tahmini, şokların iletim kanallarının türü gibi birçok farklı faktöre bağlı olduğu görülmektedir.

Çalışma sonucunda Türkiye'de 1982-2015 yılları arasında HLM etkisinin olduğu tespit edilmektedir. Ancak burada dış ticaret hadlerindeki değişmeler diğer genel çalışmalardan farklı olarak mal ticaret hadleri ve gelir ticaret hadleri olarak ayrı ayrı incelenmiştir. Buna göre analiz döneminde Türkiye'de mal ticaret hadleri ile dış ticaret dengesi arasında negatif yönlü ve anlamlı bir ilişki bulunurken, gelir ticaret hadleri ile dış ticaret dengesi arasında anlamlı aynı yönde bir ilişki olduğu sonucuna ulaşılmıştır.

Dolayısıyla mal ticaret hadleri, dış ticaret dengesi üzerindeki etkisini göreli fiyat değişmeleri yoluyla ortaya koyarken, gelir ticaret hadleri dış ticaret dengesi üzerinde etkisini hem fiyat hareketleri hem de ihrac ve ithal edilen malların miktarında yaratabileceği etkiler kanalıyla gösterecektir. Bu nedenle iki endeksinde dış ticaret dengesi üzerine etkisi ayrı ayrı analiz edilmiştir. İlk analiz mal ticaret hadlerinin diş ticaret dengesi etkisi üzerine yapılmıştır. Bulgularımız mal ticaret hadleri ile dış ticaret dengesi arasında anlamlı ve negatif bir ilişkinin olduğunu ortaya koymaktadır. Mal ticaret hadlerinde oluşacak \%1'lik bir değişmenin ticaret dengesini yaklaşık olarak kendisi kadar ve negatif yönlü değiştireceğini göstermektedir. Kısa dönem hata düzeltme terimi negatif ve istatistiksel olarak anlamlıdır. Bir dengesizlik durumunun uzun dönem dengeye uyarlanması yaklaşık olarak üç dönem sonra gerçekleşmektedir.

Bu durum Türkiyenin ihraç ettiği malların fiyatlarının ithal ettiği malların fiyatlarına göre yükselmesi durumunda $\left(P_{x t} / P_{m t}\right)$ dış ticaret dengesinin bozulduğunu göstermektedir. Bu bulgular Obsfeld (1982) ve kısmi olarak ta Otto (2003) bulgularıyla tutarlıdır ve açıklanması gerekir. Zira mal ticaret hadlerinin iyileşmesinin (bozulmanın) dış ticaret dengesini bozduğu (iyileştirdiği) gibi bir sonuç elde edilmiştir. Bu nedenle gelir ticaret hadleri ile dış ticaret dengesi 
arasındaki ilişki de incelenmiş ve aralarında anlamlı ve pozitif bir ilişki bulunmuştur. Uzun dönemde gelir ticaret hadlerinde oluşacak \%1'lik bir değgişme ticaret dengesini aynı yönde bu değişmenin \%10'u civarında değiştirecektir. Hata düzeltme terimi negatif ve istatistiksel olarak anlamlıdır. Hata düzeltme terimine göre, oluşacak bir dengesizliğin uzun döneme uyarlanması yaklaşık 4 dönem sürmektedir. Gelir ticaret hadlerinin pozitif etkisi, fiyat etkisininin ortaya çıkardığı miktar etkisiyle ilgili olabilir. Bu durumda Türkiye'nin ihraç ettiği malların fiyatlarındaki bir yükselme dış ticaret dengesini olumsuz etkilerken, miktar etkisi pozitif etkilemekte ve diş ticaret dengemiz iyileşmektedir. Bu sonuç ihracatımızın dış talep enekliği ve ithalatın yurt içi talep esnekliğinin toplamının katı olmasıyla açıklanabilmektedir. Diğer bir deyişle Marshall-Lerner koşulu işlememektedir.

\section{KAYNAKÇA}

Backus, D. K. (1993) "Interpreting Comovements in the Trade Balance and the Terms of Trade", Journal of International Economics, 34 (3-4):375-387.

Cashin, P. ve J. McDermott, (1998) "Terms of Trade and the Current Account", IMF Working Paper No. 177

Duncan, R. (2003) “The Harberger-Laursen-Metzler Effect Revisited: An Indirect-Utility-Function, Approach", Central Bank of Chile Working Papers No. 250

Harberger, A.C. (1950) "Currency Depreciation, Income, and the Balance of Trade", Journal of Political Economy, Vol. 58, No. 1. 47-60

Idrees, T. ve S. Tufail (2012) “The Harberger-Laursen-Metzler Effect: Evidence from Pakistan”, The Lahore Journal of Economics, 17: 2; 87-110

Kent, C. (1997) "The Response of the Current Account to Terms of Trade Shocks: A Panel-data Study", Reserve Bank of Australia

Kipıcı, A.N. (1996) "Terms of Trade and Economic Fluctuations", The Central Bank of the Republic of Turkey Discussion Paper, No:9615, 1-13

Laursen, S. ve L. A. Metzler (1950) "Flexible Exchange Rates and the Theory of Employment", The Review of Economics and Statistics, Vol. 32, No. 4; 281-299

Mendoza, E.G. (1995) "The Terms of Trade, the Real Exchange Rate, and Economic Fluctuations", International Economic Review, Vol. 36, No. 1, 101-137

Misztal, P. (2010) "The Harberger-Laursen-Metzler Effect.Theory and Practice in Poland", The Romanian Economic Journal, XIII, no. 38, 129-146

Obstfeld, M. (1982) “Aggregate spending and the terms of trade: Is there a Laursen-Metzler Effect?”, Quarterly Journal of Economics, 97, 251-270.

Oktar, S. ve L. Dalyancı (2012) "Dış Ticaret Hadlerinin Cari İşlemler Dengesi Üzerindeki Etkisi: Türkiye Örneği”, Marmara Üniversitesi, İ.İ.B. Dergisi, sayı:2,1-18

Otto, G. (2003) "Terms of trade shocks and the balance of trade:there is a Harberger-Laursen-Metzler Effect", Journal of International Money and Finance, 22, 155-184

Persson, T. ve Svensson, L.E.O. ( 1985) "Current account dynamics and the terms of trade: HarbergerLaursen-Metzler two generations later”, Journal of Political Economy, 93 (1), $43-65$.

Pesaran, H.M.,Y. Shin ve R.J. Smith (2001) "Bounds Testing Approaches to the Analysis of Level Relationships", Journal of Applied Econometrics, 16, 289-326

Sachs, J. (1981) "The Current Account and Macroeconomic Adjustment in the 1970's.", Brooking Papers on Economic Activity 1: 201-68.

Sen, P. ve S. J. Turnovsky (1989) "Deterioration of the Terms of Trade and Capital Accumulation: A Re-examination of the Laursen-Metzler Effect.", Journal of International Economics, 26: 227-250.

Serven, L. (1999) "Terms-of-trade Shocks and Optimal Investment: Another Look at the LaursenMetzler Effect.", Journal of International Money and Finance, 18: 337-65. 
Svensson, L.E.O. ve Razin, A. (1983) "Terms of trade and the current account: The HarbergerLaursen-Metzler Effect", Journal of Political Economy, 91, 97-125.

Tornell, A. ve P. Lane (1994) "Are Windfalls a Curse? A Non-representative Agent Model of the Current Account and Fiscal Policy", NBER Working Paper, 4839

Wong Hock, T. (2006) "Is there a Long-run Relationship Between Trade Balance and Terms of Trade? The case of Malaysia", Applied Economics Letters, 13, 307-311

Yamak, R. ve A. Korkmaz (2006) "Harberger-Laursen-Metzler Etkisi: Literatür ve Türkiye Örneği”, Atatürk Üniversitesi, İ.I.B. Dergisi, cilt:20,s:1,57-69

\section{SUMMARY}

This study has investigated the long-run relationship between trade balance and terms of trade, namely commodity terms of trade and income terms of trade in Turkey. An increase in terms of trade could lead to an increase or a decrease in trade balance. This theoretical prediction is widely known as the HarbergerLaursen-Metzler (HLM) effect.

As far as the literature of economics is concerned, the relationship between the trade balance and the terms of trade seems to have been ambigious. According to this theoretical view known as "HLM effect", a contractionary shock recorded in the terms of trade leads to a deterrioration in the current account balance. The impact of terms of trade on current balance depends on the underlined factors: Duration of the shocks; whether occurences of such changes were estimated or not; and the channels through which such shocks affect balance of current account.

The findings of this work establish that Harberger-Laursen-Metzler effect is valid for the Turkish economy concerning the period 1982-2015. However, changes in trade balance in this respect have been defined and analyzed separately as being commodity terms of trade and income terms of trade. According to the findings concerning Turkey for the sampling period, there exist a negative and statistically significant relationship between commodity terms of trade and balance of trade; in the other side there is a positive and significant relationship between income terms of trade and balance of trade.

As for the analysis of variables in the long-run, studying the coefficients regarding the trade balance and commodity terms of trade in long-run, it is found that the relationship is negative and statistically meaningful, indicating that a $1 \%$ negative change in the commodity terms of trade changes the trade balance in equal size, but in opposite direction.

Moreover, the findings accordingly indicate a positive change in the income terms of trade that effects the trade balance in the same direction. A possible $1 \%$ change in income terms of trade changes the size of trade balance by about $10 \%$ of the size of the former in the same direction. Income terms of trade notion equally accommodates the volume of external trade. In fact, a possible loss or benefit that a country might undergo due to the changes in relative prices also depends on the changes in the volume of external trade. An actual change in income terms of trade (net exchange of terms of trade) is indeed influenced by the commodity terms of trade and changes in the volume of exports. While commodity terms of trade is expanding, volume of exports is expected to shrink. 